\title{
Analysis of maximum pressure drop for a flat-base spouted fluid bed
}

\author{
Esmail R. Monazam², Ronald W. Breault ${ }^{* 1}$ and Justin Weber ${ }^{1}$ \\ ${ }^{1}$ National Energy Technology Laboratory \\ U. S. Department of Energy \\ 3610 Collins Ferry Rd. \\ Morgantown, West Virginia 26507-0880 \\ ${ }^{2}$ REM Engineering Services, PLLC \\ 3537 Collins Ferry Rd. \\ Morgantown, West Virginia 26505
}

\begin{abstract}
For design purposes of the blower power requirements during startup of a spouting bed process, knowledge of the maximum pressure drop across a spouting bed at the onset of spouting is required. A survey of the literature for this information lead to only a few correlations which required information from a spouting bed test to be applicable. Therefore, an experimental investigation of this pressure drop and its associated superficial gas velocity in a flat based spouted bed operating with and without fluidization has been conducted.Measurements were performed using a10 $\mathrm{cm}$ cylindrical bed with different static bed heights and two Geldard group B particles $\left(\mathrm{Al}_{2} \mathrm{O}_{3}\right.$ and $\left.\mathrm{HDPE}\right)$. The results show that thetaller static bed height creates a larger maximum pressure drop across the bed, as expected. The maximum pressure drop also increases with increasing fluidized gas velocity.The evolution of maximum pressure drop and its velocity were evaluated and a correlation for the maximum pressure drop and its corresponding velocity for spouted and spouted fluid beds were obtained.
\end{abstract}

\section{Introduction}

The development of spouted beds has been pursued due to several limitations of conventional fluid beds, such as the formation of large bubbles, slugging, and difficulty of fluidizing certain coarse particles(Sutkar et al., 2013).By improving the hydrodynamicsbehavior of the particles in the bed, better reaction performance, mixing, and avoidance of agglomerates can be achieved.

In spouted beds the high velocity gas flows through a small openingorifice (i.e. $\mathrm{d}_{\mathrm{j}} \sim 25 \mathrm{~d}_{\mathrm{p}}$ ) in the base of the bed causing the particulate phase to be lifted within a bed of solids. These particles fall back on the surrounding annular region which leads to solid circulation within the bed, proportional to the gas flow rate. The particles then flare out into the annulus, and eventually move inward back to the spout. Due to this unique hydrodynamic behavior,spouted beds have been used in many applications such as pyrolysis (Arabiourrutia et al., 2007;Makibar et al., 2012), combustion (Rasul,2001), gasification (Bernocco et al., 2013), coating (Martins et al., 2008) and drying (Benelli et al., 2013). The main advantage of the spouted bed is a cyclic pattern

*Corresponding author: Tel. 304-285-4486; fax: 304-285-4403; email:ronald.breault@netl.doe.gov 
of solids movement which enhances the heat and mass transfer between gas and solids as well as the long solids residence time(Makibar et al. 2011,Kmiec et al. 2009).However, there areimportant limitationssuch aslow annulus aeration which may cause dead zones and particle agglomeration, high pressure drop prior to onset of spouting, and slow solids turnover (Rovero et al., 2012).One of many modifications to the spouted bed is spouted fluidized bed (Zhong et al., 2006, 2008) which is achieved by introducing additional gas flow into annular region of a spouted bed. The spouted fluidized bed reduces the particle agglomeration, improves the gassolid contact, and enhances mixing.

The hydrodynamic characteristics of different types of particles in spouted fluidized beds have been subject of interest for many researchers. The concept of spouted fluidized bed was first introduce by Chatterjee (1970). Chatterjee concluded that the minimum spouting-fluidization air mass flow rate is $36 \%$ lower than the summation of the minimum spouting and minimum fluidizing air mass flow rate for the same system. In other words, the annular fluidization significantly reduces the gas flow needed to produce a spout due to the increased mobility of the fluidized solids. Nagarkatti and Chatterjee (1974) have determine experimentally that the sum of auxiliary and central flow at the minimum spouting with aeration is equal tothe minimum spouting flow rate.Nagashima et al. (2015)demonstratedthat the particle velocities in the spout and the annulus were increased byincreasing the auxiliary gas velocity.They also concluded that the minimum spouting gas velocity for stable spouting state (spouting with aeration) decreases with increasingauxiliary gas velocity. Recently Sutkar et al. (2013) presented a review of recent advances in experimental and numerical studies of spouted fluidized beds. They concluded that the pressure drop in a spouted fluidized bed increases with increasing bed height, spout diameter, and density of the particles, whereas the pressure dropdecreases with increasing particle diameter and spout gas velocity.

The primary objective of this research is to gather hydrodynamic data with beds operated as both spouted bed and spout-fluidized bed with a flat base. The hydrodynamic parameters of interest are the maximum pressure drop and the velocity at which maximum pressure drop occur. This study also investigates the effect of operating parameter such as static bed height, fluidizing gas velocities, and particle characteristics on the maximum pressure drop and velocity at the point of maximum pressure drop. The knowledge of the maximum pressure drop can be used to determine the operating power or air compressor requirements during the design of spouted beds.

\section{Experiments}

Experiments were conducted in a flat base cylindrical bed with an internal diameter of $10 \mathrm{~cm}$ and a height of $183 \mathrm{~cm}$ from the top of the plenum to the gas exit level (see Figure 1). The spouted bed columns are constructed from clear polyvinyl chloride (PVC) pipe and consist of one-piece column attached to a flat base. The column sits at the top of a plenum base. The gas inlet orifice for the gas jet is approximately $0.32 \mathrm{~cm}(1 / 8$ inch) in diameter.It should be noted that the ratio of bed to inlet orifice diameter is about 31.5 which satisfy the criteria $(\mathrm{D} / \mathrm{dj}>12)$ proposed by Mathur and Epstein (1974) for stable spouting.

Air was used as the spouting and fluidization medium and wascontrolledusing Alicat mass flow controllers. For the spouted bed, air was introduced into the bed using flexible tubing that was routed inside the plenum, through the center of the distributor plate, and protruded $1.27 \mathrm{~cm}$ into the bed. In the spout-fluidized bed, the same fluidizing air from spout as previously described 
was used along with auxiliary fluidizing air source that fed the plenum. The fluidizing air being fed into the plenum is released into the bed via the distributor plate. Therefore, both the air sources for the spout and distributor are controlled independently. As the air moves up the spouted bed and reaches the bed surface, a fountain region is formed. The solids then fall back onto the bed surface by gravity with the solid velocity at theterminal velocity, thus feeding the annulus region with solids. This creates asystematic cyclic movement of particles in the spouted beds (Figure 1). The maximum concentration of gas phase is in the spout region and the annulus regionhas the lowest concentration of gas phase in the spouted bed. Particle mixingis very strong at the bottom of annulus due toits movement to entrain into spout.

The distributor was a perforated plate consisting of 25 symmetrical orifices, $1.59 \mathrm{~mm}$ in diameter. A stainless steel screen mesh, U.S. No. $325(44 \mu \mathrm{m})$ sized, was placed under the distributor plate to prevent the materials from escaping the fluidized bed and falling into the plenum chamber. At the top of the fluidized bed column, the same stainless steel screen mesh was attached to prevent any particles larger than $44 \mu \mathrm{m}$ that had elutriated from escaping the experimental unit. It should be noted that the center orifice of the existing fluidized bed distributor plate was enlarged to allow for the $0.64 / 0.3175 \mathrm{~cm}$ (OD/ID) tube to be inserted through the distributor plate to act as the spout that would stand $1.27 \mathrm{~cm}$ in height from the bottom of the bed. For these tests, the criteria by Mathur and Epstein (1974)D/dj = >12 for stable spouting has been met.

The pressure drop measurements were provided by two pressure taps using a Rosemont differential pressure transmitters at a sampling rate of $60 \mathrm{~Hz}$. The pressure taps are place at 3.8 and $57.2 \mathrm{~cm}$ from the bottom of the bed. Each differential pressure transducer has two ports, one located in the wall of the bed column and the other connector to the fluidizing gas plenum as shown in Figure 2. All data was collected and stored using Paragon control system. The experimental operating pointsare presented in Table 1.It should be noted that the ratio of inlet orifice to particle diameters ranged from 3.6 to 11.6 for the tests. These dimensions satisfy the criteria $\left(\mathrm{d}_{\mathrm{j}} / \mathrm{d}_{\mathrm{p}}<25-30\right)$ proposed by Chandnani and Epstein (1986) for stable spouting.Several experiments were conducted with the test conditions summarized in Table1.

Two different particulate materials, namely high density polyethylene (HDPE) and aluminum oxide $\left(\mathrm{Al}_{2} \mathrm{O}_{3}\right)$, were used to cover a sufficient range of parameters. See Table 2 for the particle properties.

\section{Results and discussion}

The hydrodynamic behavior of the spouted bed is most easistdescribed with a plot of bed pressure drop as a function of gas velocity (Figure 3). Spouting can be obtained from the static bed conditions denoted in Figure 3, which shows a typical plot of the bed pressure versus the spouting gas velocity (superficial gas velocity at the top of the bed). Beginning at point " $\mathrm{A}$ " in Figure 3 the pressure drop increases linearly with increasing gas velocity and approaches the maximum pressure drop ( $\Delta P_{M}$ at point $\left.\mathrm{B}\right)$. The peak part of the pressure drop profile due to sudden rise and fall in pressure drop values indicates the spout formation and breaking of the spoutrespectively.From the Figure 3, it is also observed that the maximum bed pressure drop $\left(\Delta p_{\max }\right)$ of HDPE particle is about $1.82 \mathrm{kPa}$.

The gas velocity at the point of maximum pressure drop is referred to as $U_{M}$. The gas velocity was set to fluctuate following a sine wave between two points of minimum and maximum 
velocities. The occurrence of maximum pressure drop is usually attributed to the energy required by the gas jet to rupture the packed bed structure and to form an internal spout in the lower part of the bed.From the Figure 3, it is also observed that the gas velocity at the point of maximum pressure drop $\left(U_{M}\right)$ of HDPE particle is about $0.163 \mathrm{~m} / \mathrm{s}$.

The experimental pressure drop for the spouting with fluidizedbed are illustrated in Figure 4. In this figure, fluidizing gas was supplied at a constant flow rate for a given $U_{g} / U_{m f}(0,0.25$ and 0.75 ) while the spouting gas was increased until a point was reached where there was a sudden decrease in bed pressure drop (Figure 4). The fluidizing gas was varied in the range from no flow to $U_{g}=U_{m f}$. Figure 4 indicates that the bed pressure drop increases slightlywith increasing the fluidized gas for given bed height $(H / D=4.5)$. However, this figure also shows that the velocity at which the pressure reaches its peak decreases $\left(U_{M}=0.163,0.13\right.$, and $\left.0.07 \mathrm{~m} / \mathrm{s}\right)$ with increasing the $U_{g} / U_{m f}(0,0.25$ and 0.75$)$.

The influence of gas velocities on pressure drop across the spouted bedwith no fluidizing gas is illustrated in Figure 5 for three different static bed height $(H / D=4.5,3$, and 1.5). In this figure, an increase in maximum pressure drop can be observed when static bed heightincreases for the same superficial gas velocity. An increase in static bed height leads to the increased resistance of the bed material, hencecreates a larger pressure drop which the spout must overcome.

Observation of the data in Figure 5 indicates that the trend is not linear with bed height. The increase in pressure drop between an H/D ratio of 1.5 to H/D ratio of 3 is more than twice the increase in pressure drop for the H/D increase from 3 to 4.5 .

Figure 6 shows the effects of particle characteristics(density and size) on the pressure drop. Upon first inspection, this trend appears to be related to the particle density as the pressure drop for the $\mathrm{Al}_{2} \mathrm{O}_{3}$ is much greater than the pressure drop for the HDPE. Taking the ratio of the pressure drop at a specific spouting velocity (say $0.17 \mathrm{~m} / \mathrm{s}$ ) gives value for the ratio of 2.8. The density ratio for these two materials is 4.64 . Thus, the density ratio is not the only parameter affecting the pressure drop. Noting that the trend for the pressure drop is linear with velocity, it is theorizedthat the viscus term of the Ergun relationship dominates this pressure drop for the flow through the packed bed. A simple partition of the contributions reveals that $87 \%$ of the total pressure drop is due to the linear (viscus) portion of the Ergun relationship. This relationship, assuming for the moment that the voidage is the same, is inversely proportional to the particle diameter squared. Calculating this value gives 2.5, close to the value of 2.8 for the pressure ratio. Therefore, the spouting bed operating at velocities below the maximum pressure drop operate in the viscus regime and that the difference in the pressure drop for different materials is caused by the particle size and not the density.

Figure 7 shows the effect of fluidizing gas velocities on the maximum pressure drop for different static bed height. As illustrated in Figure 7, the maximum pressure drop increases with increasing fluidized gas velocity. It is known that large start-up pressure dropsareone of the disadvantages of spouting beds. However, the increase in maximum pressure drop is minimal for lower static bed heights as compare to the higher static bed heights. The effect of static bed height on maximum spouted pressure drop is illustrated in Figure 8 for different fluidizing gas velocities. The maximum pressure drop also increases with increasing static bed height. This is due to the fact that the maximum pressure drop is directly proportional to the weight of bed divided by the area of the bed. Also, when the spouting gas penetrates the bed to initiate 
spouting, the smaller bed height requiresa lowermaximum pressure drop due to the resistance of less bed material.

The effect of fluidizing gas velocities on the velocity at maximum pressure drop $\left(U_{M}\right)$ for different static bed heights is shown in Figure 9. It is also seen from Figure 9 that the $U_{M}$ decreases linearly withincreasing fluidizing gas velocitiesfor all thestatic bed height tested in this work.Increasing fluidizing gas velocity might lead to more gas transfer from annular region to the central spout region leading to decreasing $U_{M}$. As fluidizing gas increases, intensive gas and solid phase redistribution over the annular and spouted zones of the bed may also slow the spouting gas momentum.

Figure 10 shows that increasing the static bed height, also increases the velocity for maximum pressure drop. As the static bed height increases, the bed weight and drag force causes themaximum pressure drop to increase.

One set of experiments was repeated to provide a measure of error for the work. This repeated test data is presented in Figure 11. The figure presents the mean of the measurements with error bars for the range of the data. The repeat test produced data within in 10\%, specifically, the error at $\mathrm{H} / \mathrm{D}$ values of $1.5,3$ and 4.5 was $8.7 \%, 5.0 \%$ and $0.7 \%$, respectively.Additionally, the linear fit for the new figure using the mean values has an $\mathrm{R}^{2}$ value of $99.52 \%$.

\subsection{Correlations}

As stated above, the maximum pressure drop $\left(\Delta P_{\max }\right)$ and its velocity $\left(U_{M}\right)$ are of practical interest in the design and operation of a spouted beds. Thus, the development of correlations for these parameters are necessary. Dimensionless analysis also helps one to understand how thetypical value of the dependent variable changes when anyone of the independent variables is varied, while the otherindependent variables are held constant.

\subsubsection{Maximum pressure drop}

Attempts were made to predict the maximum pressure drop using some existing correlations available in the literatures for the present experiments. Numerous researchers have developed correlations to predict the maximum pressure drop for spouted beds(Asenjo et al., 1977; Yokogawa and Isaka, 1971; Ogino et al., 1993; Olazar et al., 1994), a list of these correlations is listed in Table 3.

Figure 12compares the experimental peak pressure drop with those listed in Table 3.The results of these comparisonsshowsthat the correlation of Ogino et al. (1993) predicts the experiment data the best as compared to the other correlations (see $\mathrm{R}^{2}$ and slopes in Table 3 ). The values of the slope and $\mathrm{R}^{2}$ parameters provide a measure for the goodness of fit between the model and the experimental data. A good model needs to have a slope near 1 so that the predicted values are nominally equal to the measured values. Additionally, when predicted values are plotted against the experimental value, the correlation coefficient $\left(\mathrm{R}^{2}\right)$ needs to be close to 1 , indicating that the predicted value and the experimental value are linearly related, i.e. equal to one another. The equation by Ogino provides a reasonable fit for the experimental data (slope near 1 and $\mathrm{R}^{2}$ near 1). However, the model of Ogino as well as the others require knowledge of an additional 
parameter such as the bed density or spouting pressure. A self-contained model that can accurately predict the maximum pressure drop without unknown parameters is desired.

According to a dimensional analysis by various researchers(Asenjo et al., 1977; Yokogawa and Isaka, 1971; Ogino et al., 1993; Olazar et al., 1994), themaximum pressure drop depends on: $H$, $D, d_{p}, d_{j}, \rho_{s}-\rho_{g}, \rho_{g}, g, \mu$.Therefore, the maximum pressure dropcan bewritten as follows:

$$
\Delta P_{\max }=f\left(U_{M}, H, D, d_{p}, d_{j}, \rho_{s}-\rho_{g}, \rho_{\mathrm{g}}, g, \mu\right)
$$

In addition to Eq. (1), He et al. (1997) also proposed particleproperties such as sphericity $\left(\phi_{\mathrm{s}}\right)$, particle interfacial angle $(\varphi)$, loose packed voidage $\left(\varepsilon_{0}\right)$, dimensionless particle size distribution and dimensionless bed geometry.By using dimensional analysis to take into account the main physicalparameters, the maximum pressure drop can be summarized as;

$$
\frac{\Delta P_{\max }}{\rho_{g} U_{M}^{2}}=f\left(\frac{d_{p}}{D}, \frac{d_{j}}{D}, \frac{H}{D}, \frac{\rho_{s}}{\rho_{g}}, A r\right)
$$

A relationship among dimensionless numbers is expressed by the following nonlinear power equation:

$$
\frac{\Delta P_{\max }}{\rho_{g} U_{M}^{2}}=a\left(\left(\frac{d_{p}}{D}\right)^{b},\left(\frac{H}{D}\right)^{c},\left(\frac{\rho_{s}}{\rho_{g}}\right)^{d}, A r^{e}\right)
$$

As in the experiments, only one jet diameter, $\mathrm{d}_{\mathrm{j}}$, was used.The ratio of $d j / D$ was not included in the determination of the correlation, due to the lack of data, and was discarded. The coefficients, $a-e$, of the above equation were obtained by a nonlinear regression analysis using SYSTAT 8 of SPSS Inc. based on the current experimental data. This analysis resulted in the following correlation:

$$
\frac{\Delta P_{\max }}{\rho_{g} U_{M}^{2}}=1.069\left(\frac{H}{D}\right)^{0.65}\left(\frac{2 g H\left(\rho_{s}-\rho_{g}\right)}{\rho_{g}}\right)^{0.3575}
$$

The coefficients were taken as the average of the upper and lower limits for the $95 \%$ confidence limits. The height of the static bed is the strongest factor in determining the maximum pressure drop, $\Delta P_{\max }$.

An expression for the velocity at maximum pressure drop, $U_{M}$, was obtained by using the same procedure as explained above:

$$
\operatorname{Re}_{, U_{M}}=11.578\left(\frac{H}{D}\right)^{0.211}\left(\frac{2 g H\left(\rho_{s}-\rho_{g}\right)}{\rho_{g}}\right)^{-0.057}
$$


Again, the coefficients were taken as the average of the upper and lower limits for the 95\% confidence limits.

The comparison between experimental values ofmaximum pressure drop and $\mathrm{Re}_{, U \mathrm{u}}$ and the corresponding values obtained throughEqs. (4) and (5) are shown in Figures13and 14. On these figures the straightline represents the correlation while the markers are the corresponding experimental results. Good agreement between the experimental and calculated points are observed with the largest relative errorsof $9.5 \%$ and $3.8 \%$ with the average deviations of $6 \%$ and $2 \%$ for equations (4) and (5) respectively. The averaged relative deviation(ARD) were calculated by:

$$
A R D=\sqrt{\frac{\sum\left(\frac{(c a l-\exp )}{\exp }\right)^{2}}{N}}
$$

Though the maximum pressure drop and its velocity are two important parameters in the design and operation of a spouted fluid bed, there is no correlation available that considers the effect of fluidizing gas on maximum pressure drop and its velocity.

Again, according to the analysis above and literature, the relevant variables for development of the correlation for the maximum pressure drop for spouted fluid bed can be arranged as:

$$
f\left(\Delta P_{\max }, H, D, d_{p}, d_{j}, \rho_{g}, \rho_{s-} \rho_{g}, \mu, g, U_{M}, U_{g}, U_{m f}\right)=0
$$

Considering the constituting variables given in Eq. (7) and using dimensional analysis, the following equation is obtained:

$$
f\left[\frac{\Delta P_{\max }}{\rho_{g} U_{M}^{2}}, A r, \frac{\left(\rho_{s}-\rho_{g}\right)}{\rho_{g}}, \frac{d_{p}}{D}, \frac{d_{j}}{D}, \frac{H}{D}, \frac{U_{g}}{U_{m f}}\right]=0
$$

Again, a relationship among dimensionless numbers is expressed by the following nonlinear power equation as follows:

$$
\frac{\Delta P_{\max }}{\rho_{g} U_{M}^{2}}=1.069\left(\frac{H}{D}\right)^{0.65}\left(\frac{2 g H\left(\rho_{s}-\rho_{g}\right)}{\rho_{g}}\right)^{0.3575}\left(1+a\left(\frac{U_{g}}{U_{m f}}\right)^{b},\left(\frac{2 g H\left(\rho_{s}-\rho_{g}\right)}{\rho_{g}}\right)^{c},\left(\frac{H}{D}\right)^{d},\left(\frac{d_{p}}{D}\right)^{e}\right)
$$

The coefficients, $a-e$, of the above equation were obtained by a nonlinear regression analysis using the SYSTAT 8 of SPSS Inc. based on the current experimental data. This analysis resulted in the following correlation:

$$
\frac{\Delta P_{\max }}{\rho_{g} U_{M}^{2}}=1.069\left(\frac{H}{D}\right)^{0.65}\left(\frac{2 g H\left(\rho_{s}-\rho_{g}\right)}{\rho_{g}}\right)^{0.3575}\left(1+2.343\left(\frac{U_{g}}{U_{m f}}\right)^{2.827}\left(\frac{2 g H\left(\rho_{s}-\rho_{g}\right)}{\rho_{g}}\right)^{0.297}\left(\frac{H}{D}\right)^{-0.843}\right)
$$


A correlation for the velocity at maximum pressure drop, $U_{M}$, was obtained using the same procedure as explained above:

$$
\operatorname{Re}_{, U_{M}}=11.578\left(\frac{H}{D}\right)^{0.211}\left(\frac{2 g H\left(\rho_{s}-\rho_{g}\right)}{\rho_{g}}\right)^{-0.057}\left(1-0.996\left(\frac{U}{U_{m f}}\right)^{1.129}\left(\frac{H}{D}\right)^{-0.209}\right)
$$

The comparisonof the experimental values ofmaximum pressure drop and Re, Uмand the corresponding values based onEqs. (10) and (11) areillustrated in Figures15and 16. The correlations and experimental data agree well with overall variance $\left(\mathrm{R}^{2}\right)$ greater than $93 \%$. On these figures the straightline represents the correlation while the markers are the corresponding experimental results.

When fitting non-linear equations with a large number ofparameters, it is prudent to consider how sensitive the trend isto the choice of input parameters, and whether equally good fitscould be achieved with different sets of parameters. Indeed, itwas found out the unknown parameters did not vary with differentinitial choices for these parameters, providing additional confidence to the findings.

\section{Conclusion}

Experiments wereperformed to characterize the gas-solid flow in a flat base spouted bed for two different particles types $\left(\mathrm{Al}_{2} \mathrm{O}_{3}\right.$ and $\left.\mathrm{HDPE}\right)$, with and without fluidizing gas. Bed pressure drop measurements were performed using a $10 \mathrm{~cm}$ cylindrical column with a flat base at the bottom. The effects of static bed height, particle propertiesand fluidizing gas velocity on the maximum pressure drop and its velocity werediscussed. Correlations for maximum pressure drop and the velocityat maximum pressure drop were developed based on a dimensionless analysis for both spouted bed and spouted fluid bed.Good agreementbetween the experimental values and the correlation for maximum pressure drop were achieved $\left(\mathrm{R}^{2}>93 \%\right)$. In addition, the experimental values of maximum pressure drop using spouted bed were compared to the correlations available in the literature.The maximum pressure drop for spouted bed was linearly proportional to the square of the particle size, the solids/gas density ratioand H/D.

\section{Notations}

$A r=$ Archimedes number, $A r=\frac{d_{p}^{3} \rho_{g}\left(\rho_{s}-\rho_{g}\right) g}{\mu^{2}}$

$d_{j}=$ inlet jet diameter $(\mathrm{m})$

$d_{p}=$ mean particle diameter $(\mathrm{m})$

$D=$ Bed diameter (m)

$g=$ acceleration due to gravity $\left(\mathrm{m}^{2} / \mathrm{s}\right)$

$H=$ Static height (m)

$\mathrm{Re}_{\mathrm{U}, \mathrm{M}}=$ Reynolds numberfor velocity at maximum pressure drop

$U_{g}=$ superficial gas velocity through plenum $(\mathrm{m} / \mathrm{s})$

$U_{M}=$ Velocity at maximum pressure dropof the spout $(\mathrm{m} / \mathrm{s})$

$U_{m f}=$ minimum fluidization velocity $(\mathrm{m} / \mathrm{s})$ 
Greek Symbols

$\mu=$ gas viscosity $(\mathrm{g} / \mathrm{cm}-\mathrm{s})$

$\rho_{g}=$ gas density $\left(\mathrm{g} / \mathrm{cm}^{3}\right)$

$\rho_{\mathrm{s}}=$ particle density $\left(\mathrm{g} / \mathrm{cm}^{3}\right)$

$\Delta P_{\max }=$ maximum pressure drop $(\mathrm{kPa})$

\section{Disclaimer}

The authors declare no competing financial interest. The U.S. Department of Energy, NETL, and REM contributions to this paper were prepared as an account of work sponsored by an agency of the United States Government. Neither the United States Government nor any agency thereof, nor any of their employees, makes any warranty, express or implied, or assumes any legal liability or responsibility for the accuracy, completeness, or usefulness of any information, apparatus, product, or process disclosed, or represents that its use would not infringe privately owned rights. Reference herein to any specific commercial product, process, or service by trade name, trademark, manufacturer, or otherwise does not necessarily constitute or imply its endorsement, recommendation, or favoring by the United States Government or any agency thereof. The views and opinions of authors expressed herein do not necessarily state or reflect those of the United States Government or any agency thereof.

\section{Acknowledgments}

The authors acknowledge the Department of Energy for funding the research through the office of Fossil Energy's Gasification Technology and Advanced Research funding programs. Special thanks go to Ky Layfield, and Joseph S. Mei for their assistance with experimental work and data.

\section{References}

Arabiourrutia, M., G. Lopez, G. Elordi, M. Olazar, R. Aguado and J. Bilbao, 2007. Product distribution obtained in the pyrolysis of tyres in a conical spouted bed reactor.Chemical Engineering Science 62(18-20), 5271-5275.

Asenjo, J. K., Munoz, R. Pyle, D. L., 1977. On the transition from a fixed to a spouted bed. Chem. Eng. Sci., 32, 109-117.

Benelli, L., C.R.F. Souza and W.P. Oliveira, 2013. Spouted bed performance on drying of an aromatic plant extract. Powder Technology 239, 59-71.

Bernocco, D., B. Bosio and E. Arato, 2013. Feasibility study of a spouted bed gasification plant. Chemical Engineering Research and Design 91(5), 843-855.

Chandnani, P.P., Epstein, N., 1986. Spouta-bility and spout destabilization of fine particles with a gas. V. Fluidization, K. Ostergaard, A. Sorensen (Eds.), Engineering Foundation, New York, pp. 233-240.

Chatterjee, A., 1970. Spout-fluid bed technique. Ind. Eng. Chem. Process Des. Dev. 9, 340-341. He, Y. L., Lim, C. J., Grace, J. R. 1997. Scale-up studies of spouted beds. Chem. Eng. Sci. 52, 329-339. 
Rovero, G., Curti, M., Cavaglià,G. 2012. Optimization of Spouted Bed Scale-Up by SquareBased Multiple Unit Design. Advances in Chemical Engineering, Dr Zeeshan Nawaz (Ed.), ISBN: 978-953-51-0392-9.

Kmiec, A., Englart, S., Ludwinska, A., 2009. Mass transfer during air humidification in spouted beds. Can. J. Chem. Eng. 87, 163-168.

Makibar, J., Fernandez- Akarregi, A.R., Isabel Alava, I., Olazar, M., 2011. Investigations on heat transfer and hydrodynamics under pyrolysis conditions of a pilot-plant draft tube conical spouted bed reactor. Chemical Engineering and Processing 50,790-798.

Makibar, J., A.R. Fernandez-Akarregi, L. Díaz, G. Lopez and M. Olazar, 2012. Pilot scale conical spouted bed pyrolysis reactor: Draft tube selection and hydrodynamic performance. Powder Technology 219, 49-58.

Martins, G.Z., C.R.F. Souza, T.J. Shankar and W.P. Oliveira, 2008. Effect of process variables on fluid dynamics and adhesion efficiency during spouted bed coating of hard gelatine capsules. Chemical Engineering and Processing: Process Intensification 47(12), 2238-2246.

Mathur, K. B., Epstein, N. 1974. Spouted Beds. Academic Press, New York. 304 p.

Nagarkatti, A., Chatterjee, A., 1974. Pressure and flow characteristics of a gas phase spout-fluid bed and the minimum spout-fluid condition. Can. J. Chem. Eng. 52, 185-195.

Nagashima, H., Kawashiri, Y., Suzukawa, K., Ishikura, T., 2015. Effects of operating parameters on hydrodynamic behavior of spout-fluid beds without and with a draft Tube. Procedia Engineering 102, 952 - 958.

Ogino, F.,Zhang, L., Maehashi. 1993. Minimum rate of spouting and peak pressure drop in spouted bed. Int. Chem. Eng. 33:2, 265-272.

Olazar, M., San José, M. J., Aguayo, A. T., Arandes, J. M., Bilbao, J., 1994. Hydrodynamics of nearly flat base spouted beds. Chem. Eng. J. 55, 27-37.

Rasul, M. G., 2001. Spouted bed combustion of wood charcoal: performance comparison of three different designs. Fuel 80(15), 2189-2191.

Sutkar, V. S., Deen, N. G., Kuipers, J. A. M., 2013. Spout fluidizedbeds:Recentadvancesinexperimentalandnumericalstudies. Chemical Engineering Science 86, 124-136.

Yokogawa, A., Isaka, M., 1971. Pressure drop and distribution of static pressure in the spouted bed. Hitachi Zosen Giho 23:1, 47-53.

Zhong, W., Chen, X., Zhang, M., 2006. Hydrodynamic characteristics of spout fluid bed: pressure drop and minimum spouting/spout-fluidizing velocity, Chem. Eng. J. 118, 37-46.

Zhong, W., Li, Q., M. Zhang, Jin, B., Xiao, R., Huang, Y., Shi, A., 2008. Spout characteristics of a cylindrical spout-fluid bed with elevated pressure. Chem. Eng. J. 139, 42-47. 
Table 1 Spouted and Spout-Fluidized Experimental Conditions

\begin{tabular}{|c|c|c|}
\hline Conditions & \multicolumn{2}{|c|}{ HDPE $(800 \mu \mathrm{m}) \mathrm{Al}_{2} \mathrm{O}_{3}(1000 \times 300 \mu \mathrm{m})$} \\
\hline Static Bed Depth (cm) & \multicolumn{2}{|c|}{$15.24,30.48,45.72$} \\
\hline Aspect Ratio, H/D & \multicolumn{2}{|c|}{$1.5,3.0,4.5$} \\
\hline $\begin{array}{l}\text { Dimensionless Velocity, } \\
U_{g} / U_{m f}\end{array}$ & \multicolumn{2}{|c|}{$0.00,0.25,0.50,0.75,1.00$} \\
\hline Gas Velocities (m/s) & $\begin{array}{l}0.00,0.032,0.064,0.095 \\
0.127\end{array}$ & $\begin{array}{l}0.00,0.052,0.104,0.156 \\
0.208\end{array}$ \\
\hline
\end{tabular}

Table 2 Tested Bed Materials Physical Properties

\begin{tabular}{|c|c|c|c|c|c|c|}
\hline \multirow{2}{*}{ Material } & \multicolumn{4}{|c|}{ Size Range $(\mu \mathrm{m})$} & \multirow[t]{2}{*}{ Sphericity } & \multirow{2}{*}{$\begin{array}{l}\text { Density } \\
\left(\mathrm{kg} / \mathrm{m}^{3}\right)\end{array}$} \\
\hline & Max & Avg & Min & SMD & & \\
\hline $\begin{array}{l}\text { High Density Polyethylene } \\
\text { (HDPE) }\end{array}$ & 1171 & 886 & 686 & 871 & 0.922 & 855 \\
\hline Aluminum Oxide $\left(\mathrm{Al}_{2} \mathrm{O}_{3}\right)$ & 845 & 613 & 307 & 551 & 0.820 & 3968 \\
\hline
\end{tabular}


Table 3. Cited correlations for maximum pressure drop

Reference
\begin{tabular}{|l|l|l|}
\hline $\begin{array}{l}\text { Asenjo et al. } \\
(1977)\end{array}$ & $\frac{-\Delta P_{\max }}{\rho_{b} g H_{0}}=1+2.8 \exp \left(-0.312 \frac{H}{D}\right)$ & $0.37,86 \%$ \\
\hline $\begin{array}{l}\text { Yokogawa } \\
\text { and Isaka } \\
(1971)\end{array}$ & $\frac{-\Delta P_{\max }}{\rho_{b} g H_{0}}=\left(\frac{d_{j}}{D}\right)^{0.14^{*}\left(D-d_{j}\right) / H}$ & $0.81,99 \%$ \\
\hline $\begin{array}{l}\text { Ogino et al. } \\
(1993)\end{array}$ & $\frac{-\Delta P_{\max }}{\rho_{b} g H_{0}}=1.15\left(\frac{H}{D}\right)^{1 / 2}\left(\frac{d_{j}}{D}\right)^{1 / 3}$ & $0.99,99 \%$ \\
\hline $\begin{array}{l}\text { Olazar et al. } \\
(1994)\end{array}$ & $\frac{-\Delta P_{\max }}{\Delta P_{s}}=1+0.35\left(\frac{H}{D}\right)^{0.1}\left(\frac{d_{j}}{D}\right)^{1.1} A r^{0.1}$ & $1.71,95 \%$ \\
\hline
\end{tabular}




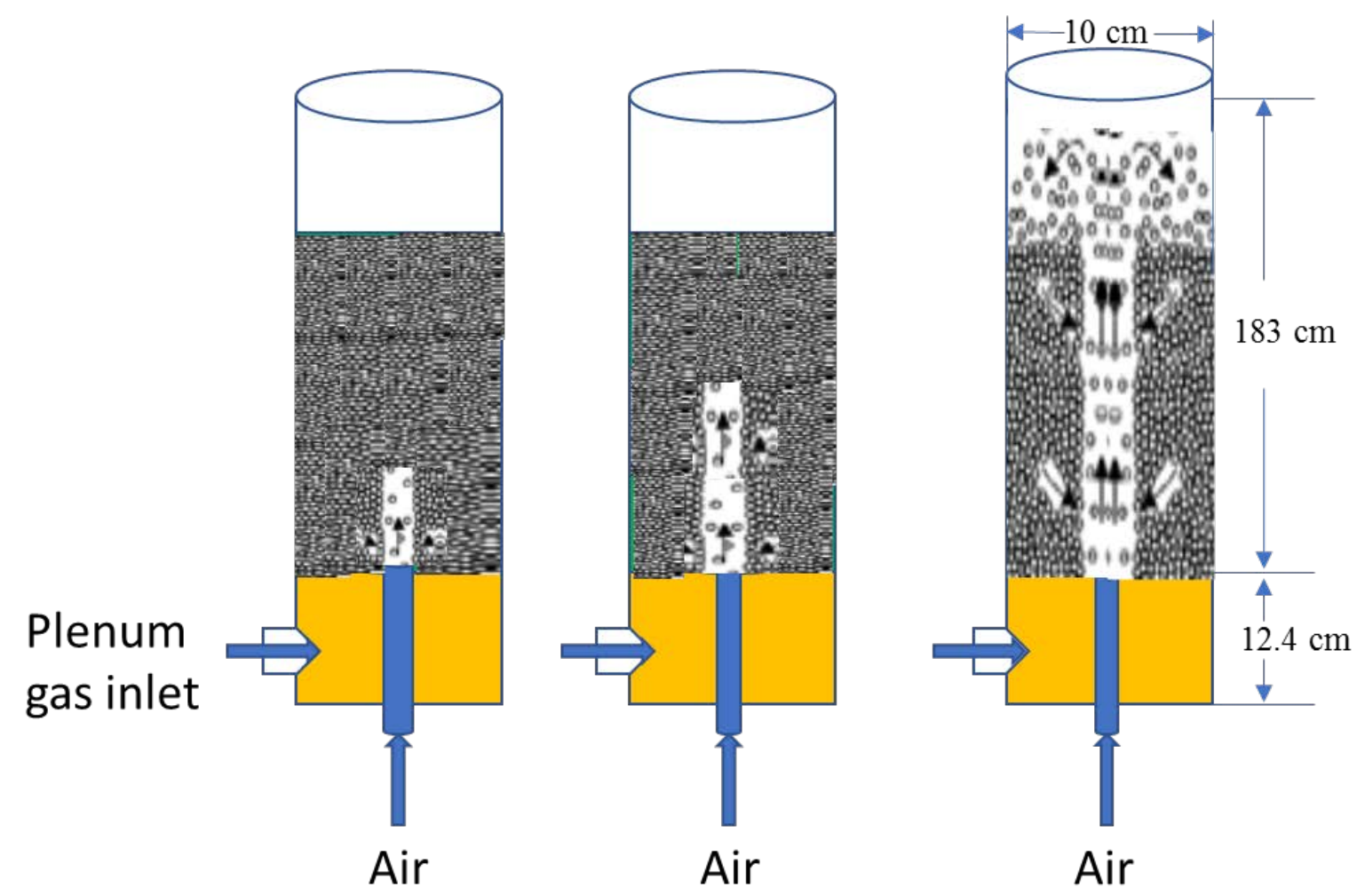

Figure 1.Conceptual spouted and spout-fluidized (using plenum gas) beds configuration 


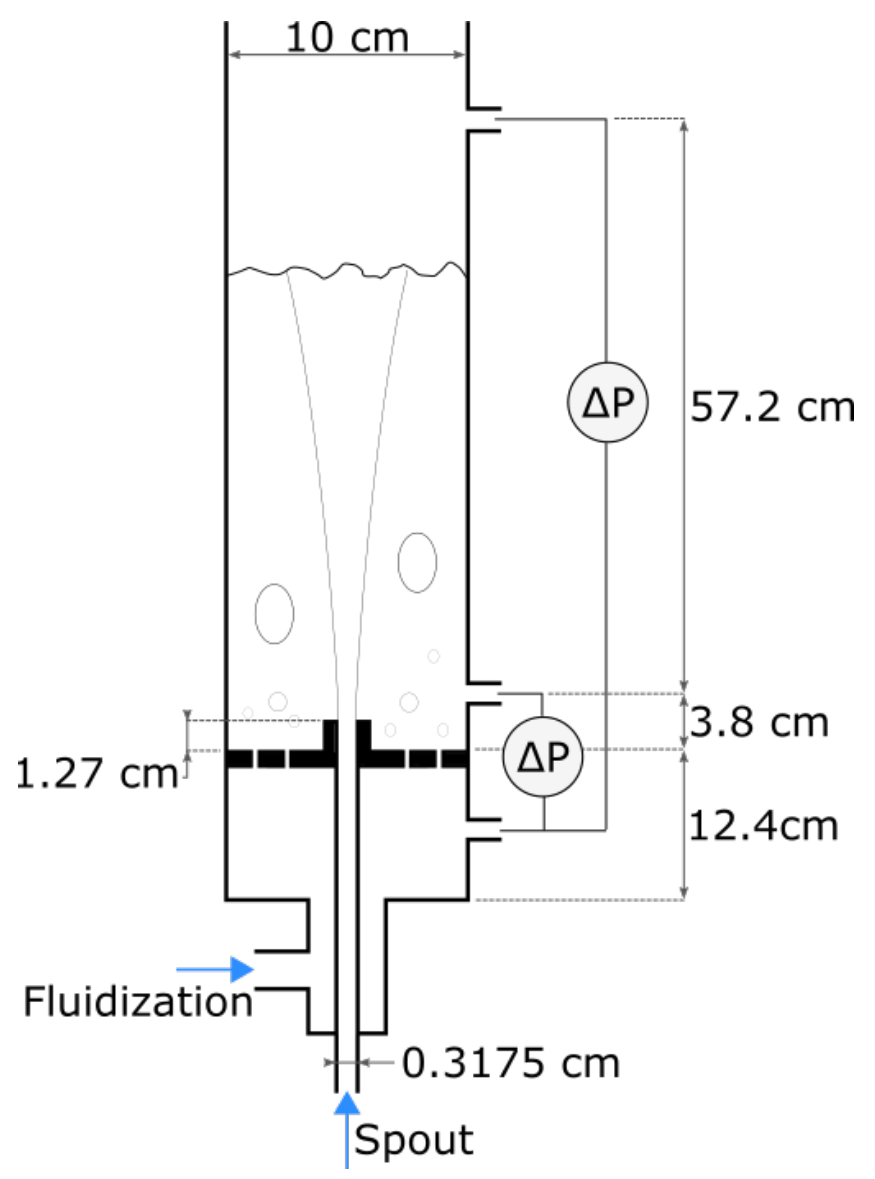

Figure 2. Experimental apparatus. 


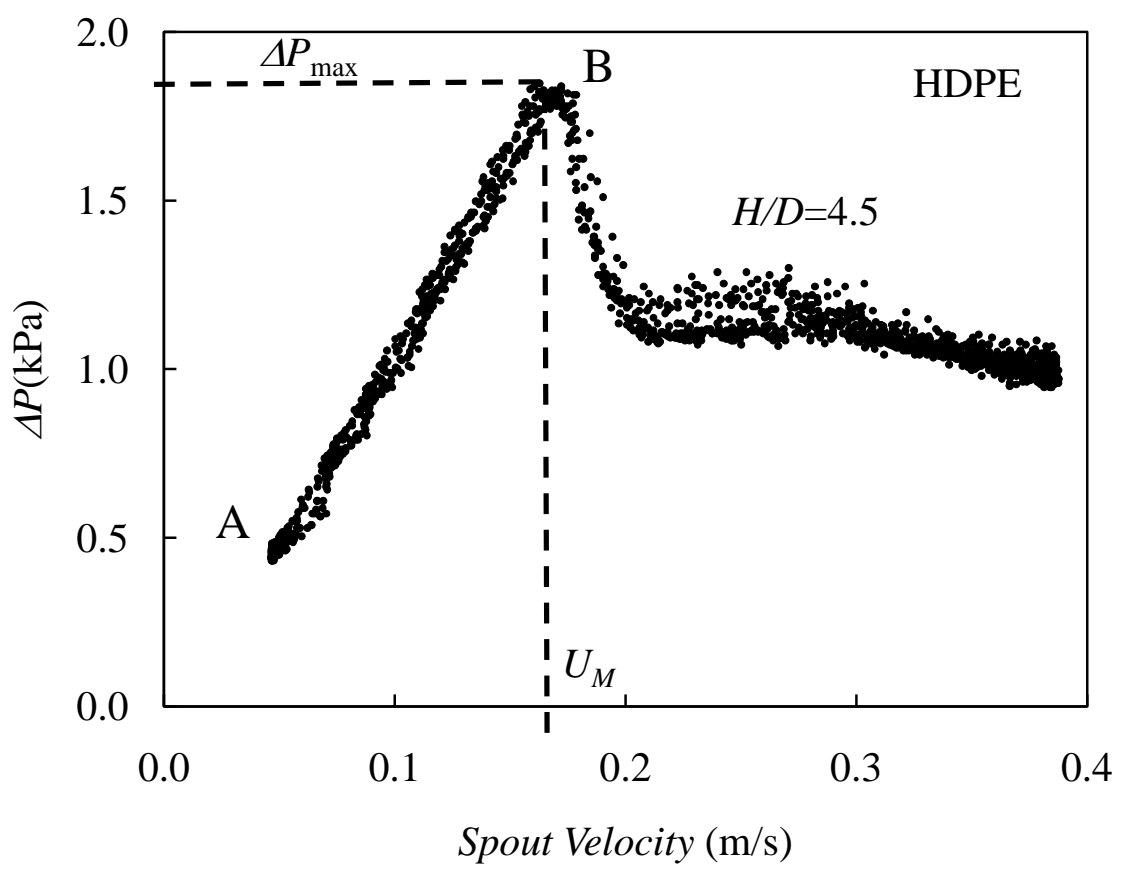

Figure 3. Typical pressure drop-gas flow rate curve (HDPE, $U_{g} / U_{m f}=0, H / D=4.5$ )

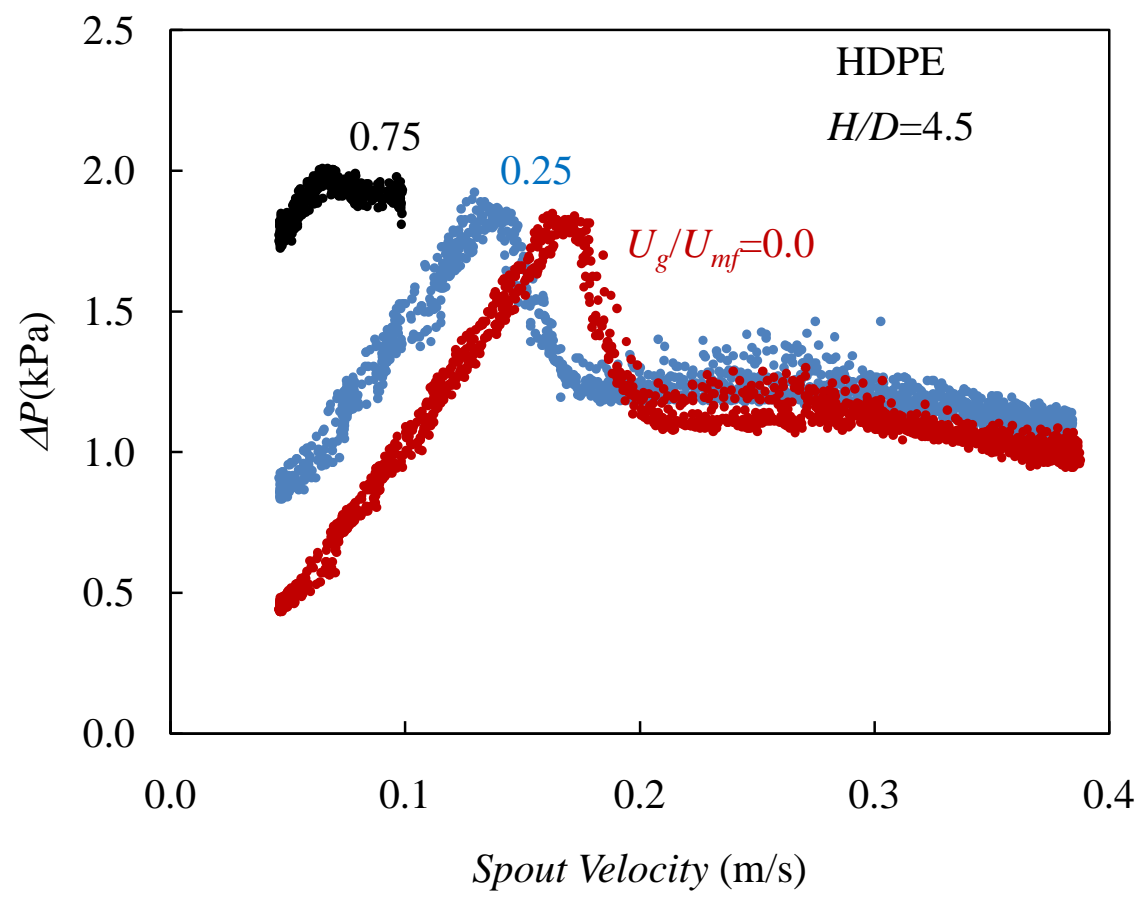

Figure 4. Effect of gas velocities on pressure drop across the spouted bed for different $U_{g} / U_{m f}\left(\mathrm{HDPE}, U_{g} / U_{m f}=\right.$ variable, $\left.H / D=4.5\right)$. 


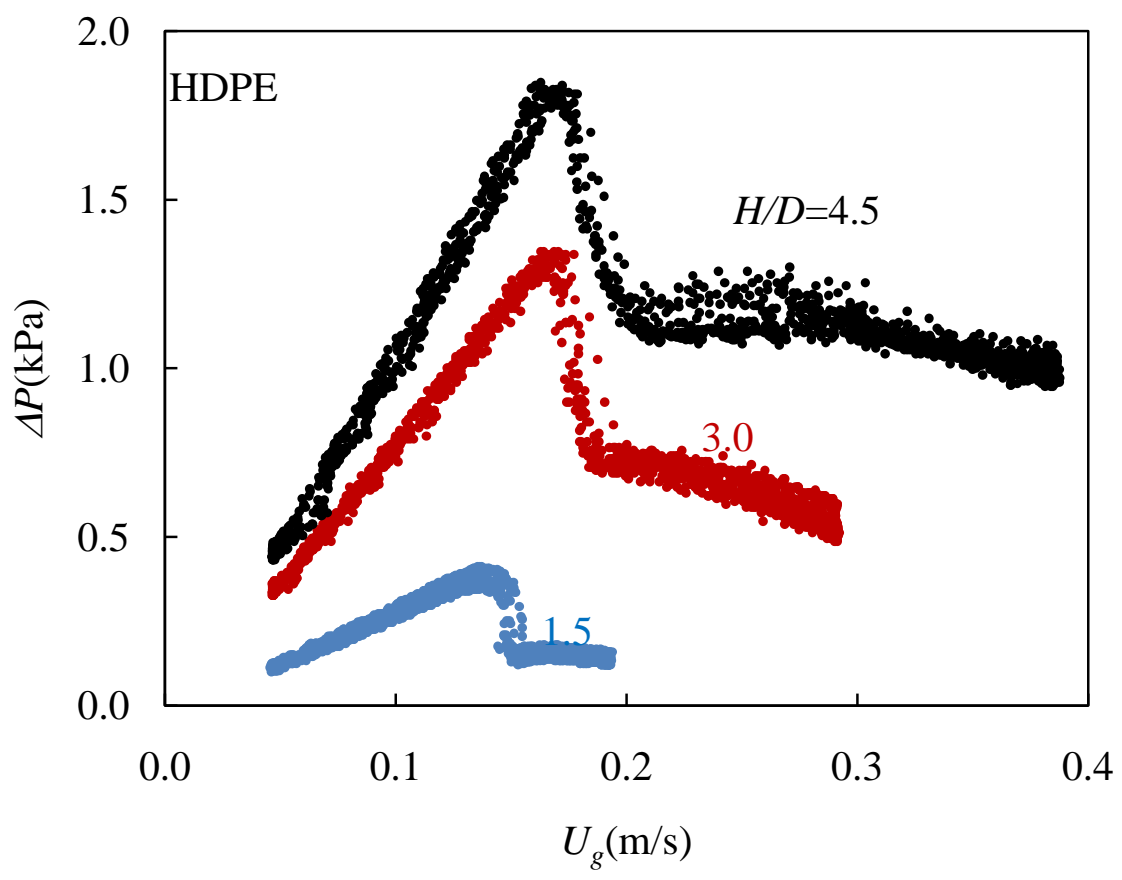

Figure 5. Effect of gas velocities on pressure drop across the spouted bed for three different static bed heightwith $U / U_{m f}=0.0$.

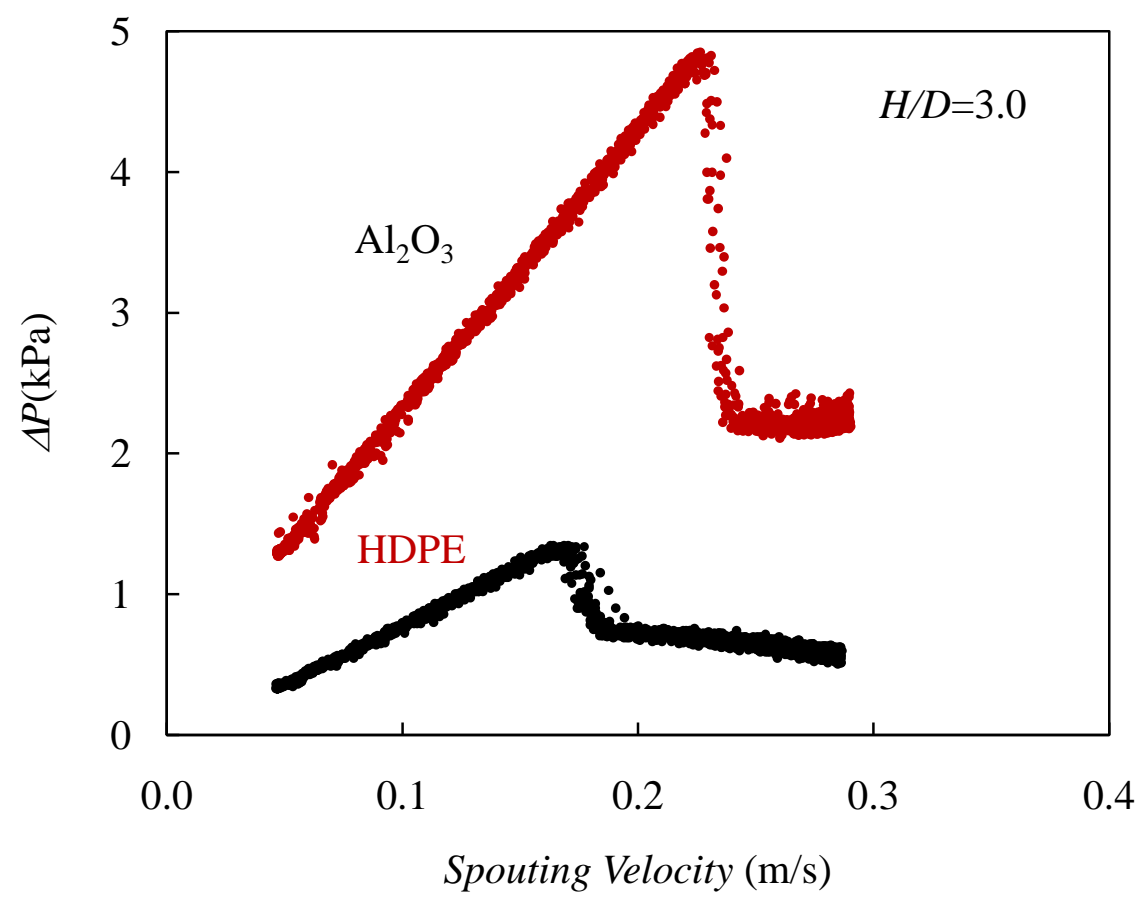

Figure 6. Effect of gas velocities on pressure drop across the spouted bed for two different particles of different sizes and densities 


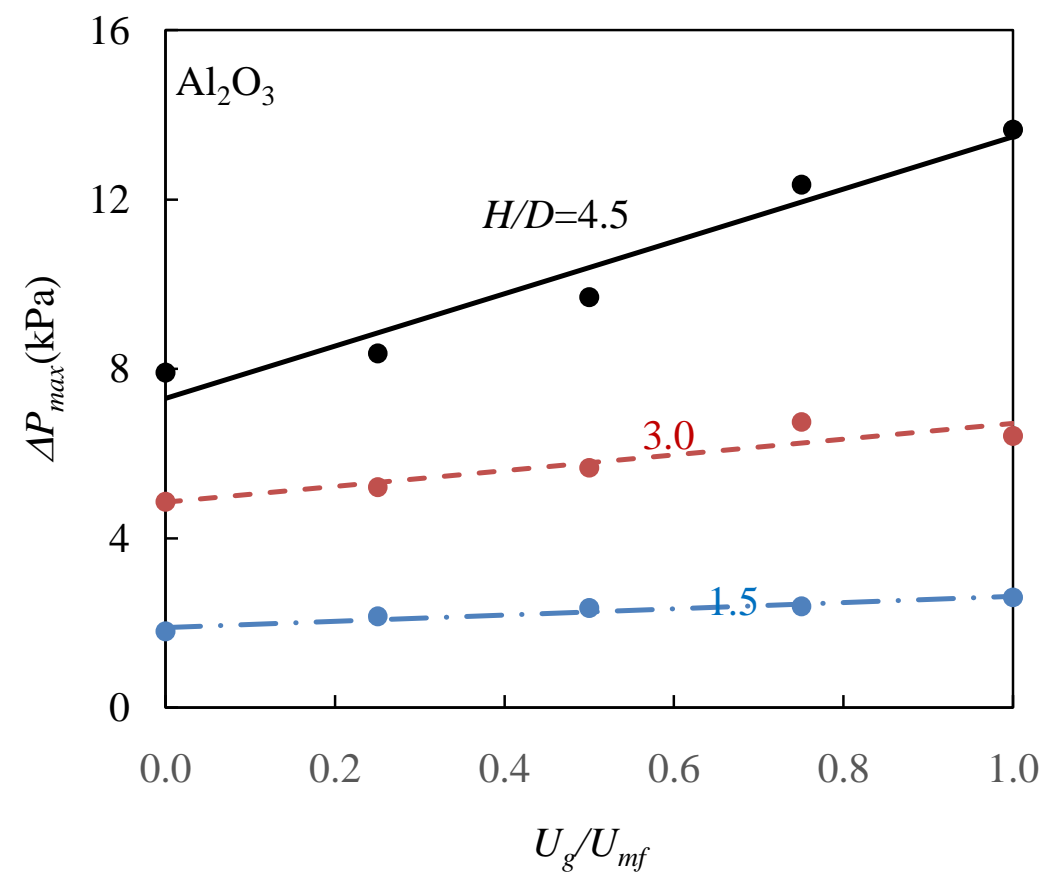

Figure 7. Effect of fluidizing gas velocities on maximum spouting pressure drop for different H/D.

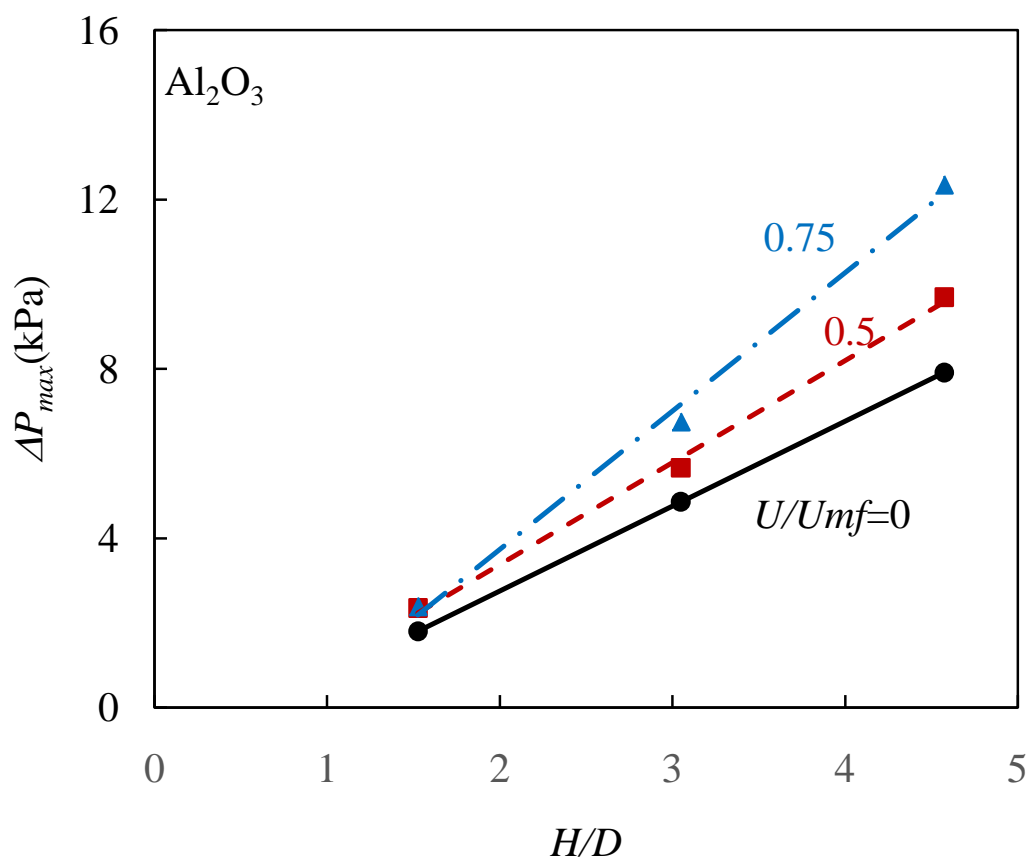

Figure 8. Effect of static bed height on maximum pressure drop for different $U / U_{m f}$. 


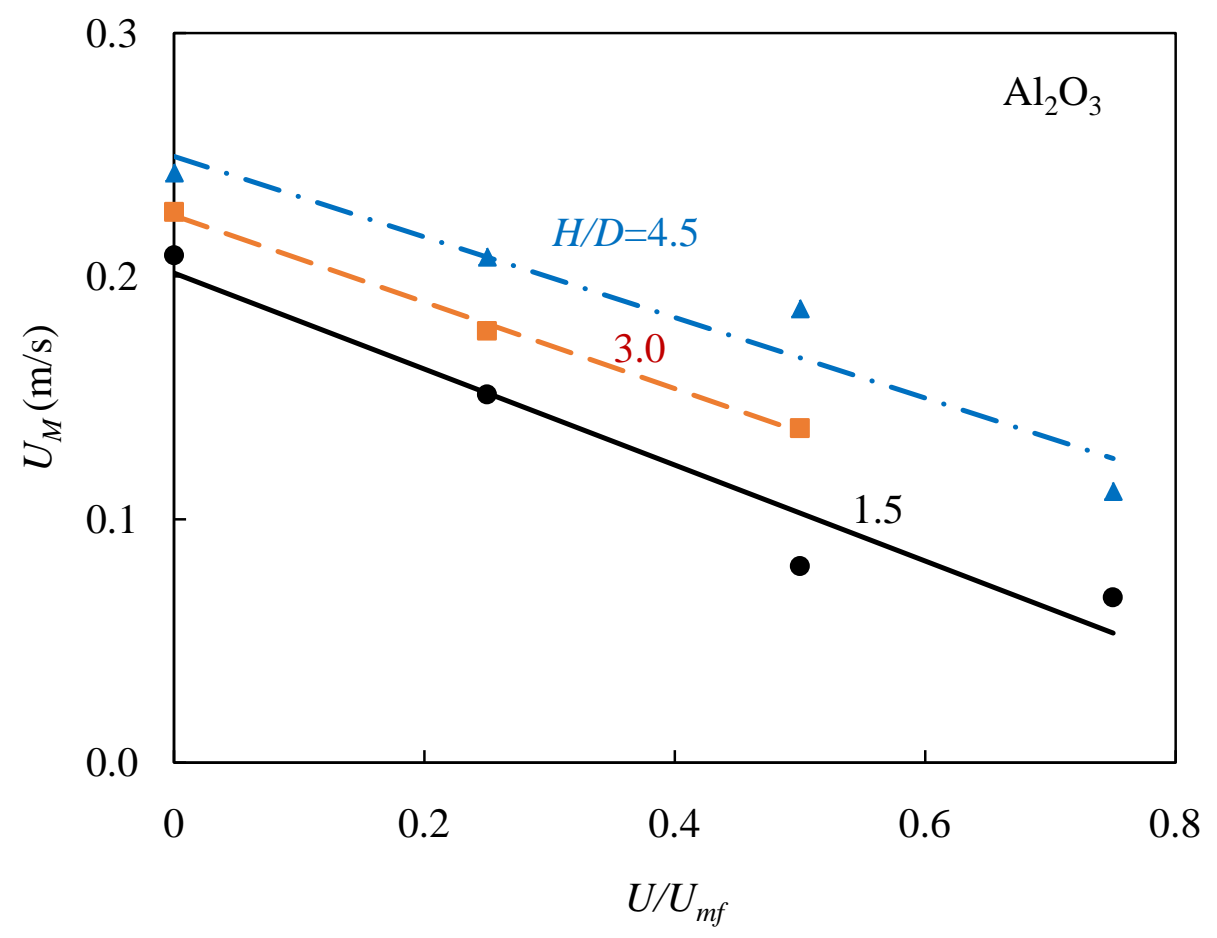

Figure 9. Effect of fluidizing gas velocities on velocities at maximum pressure drop for different H/D.

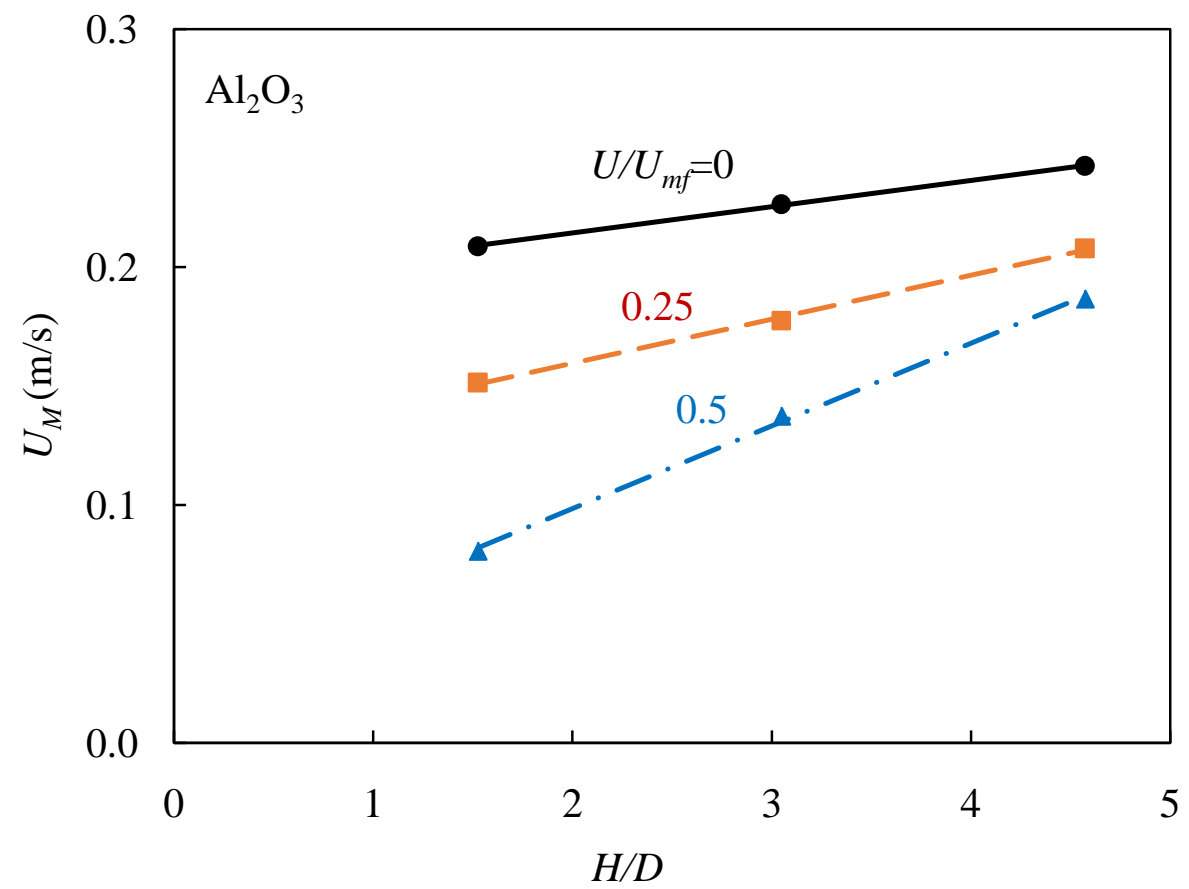

Figure 10. Effect of static bed height on velocities at maximum pressure drop for different $U / U_{m f}$. 


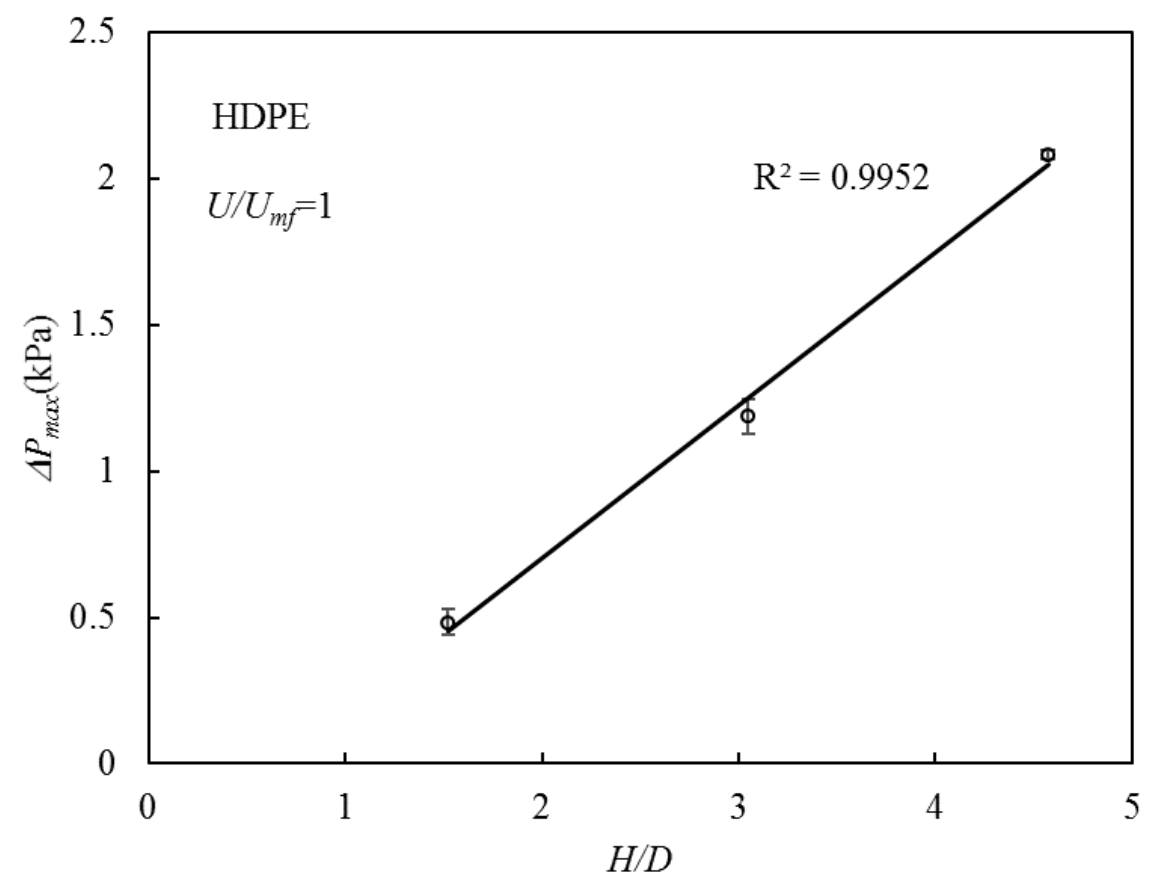

Figure 11. Repeated experiments to provide a measure of error.

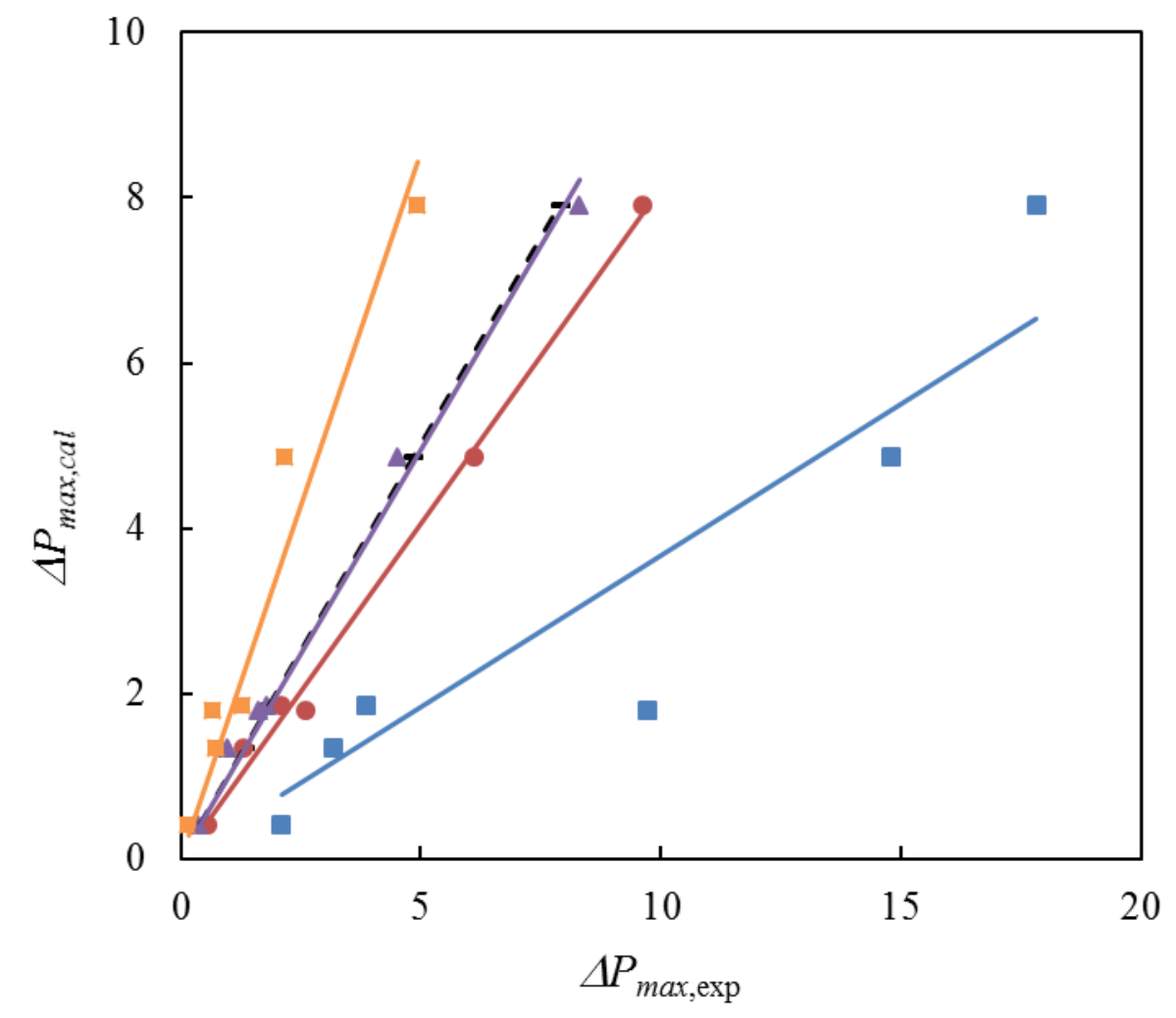

- This work

- Asenjo et al. [16]

- Yokogawa and Isaka [17]

$\triangle$ Ogino et al. [18]

m Olazar et al. [19]

Figure 12. Comparison of experimental maximum pressure drop without fluidizing gas and calculated using cited correlations. 


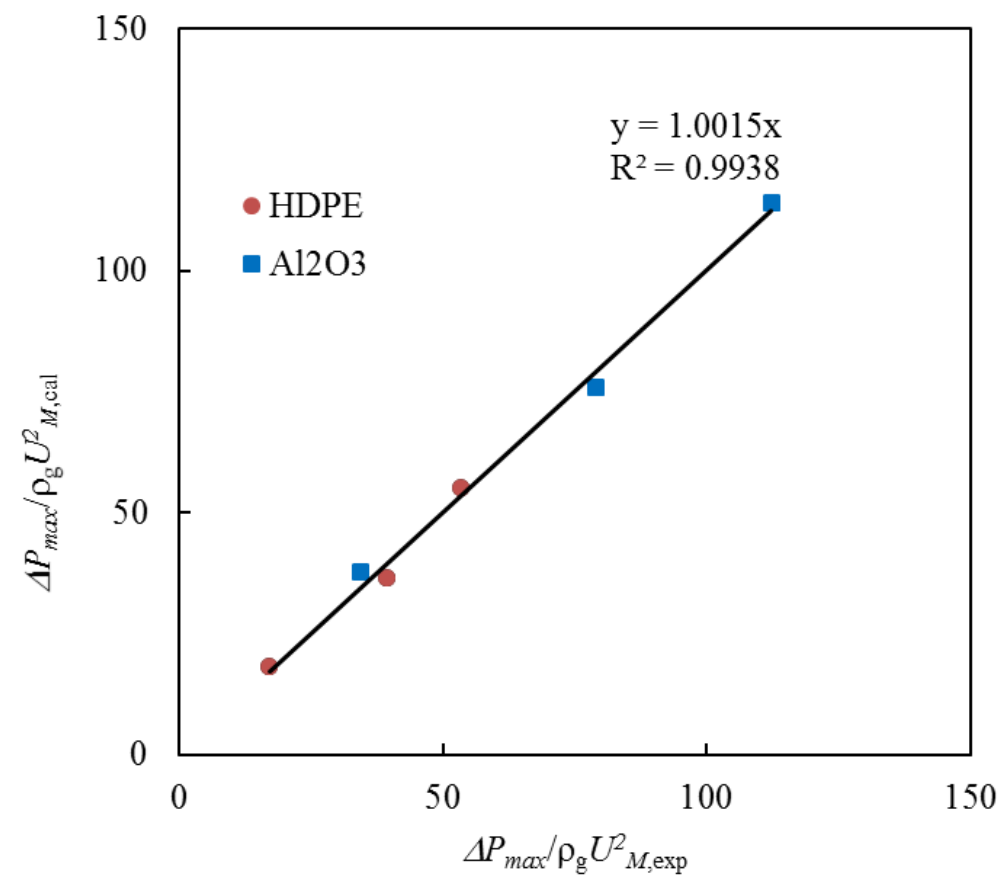

Figure 13. Comparison of the maximum pressure drop ratio without fluidizing gas using Eq. (4) with experimentally measured values.

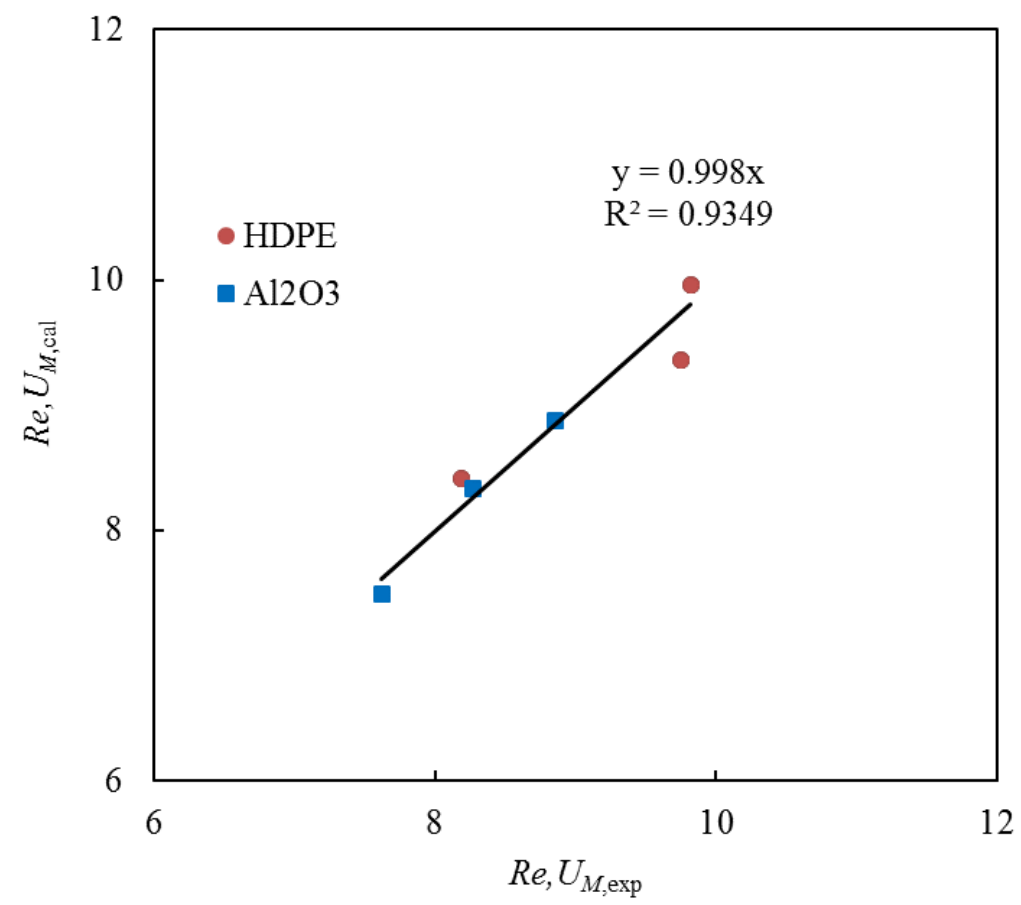

Figure 14. Comparison of the Re\# at maximum pressure drop without fluidizing gas using Eq. (5) with experimentally measured values. 


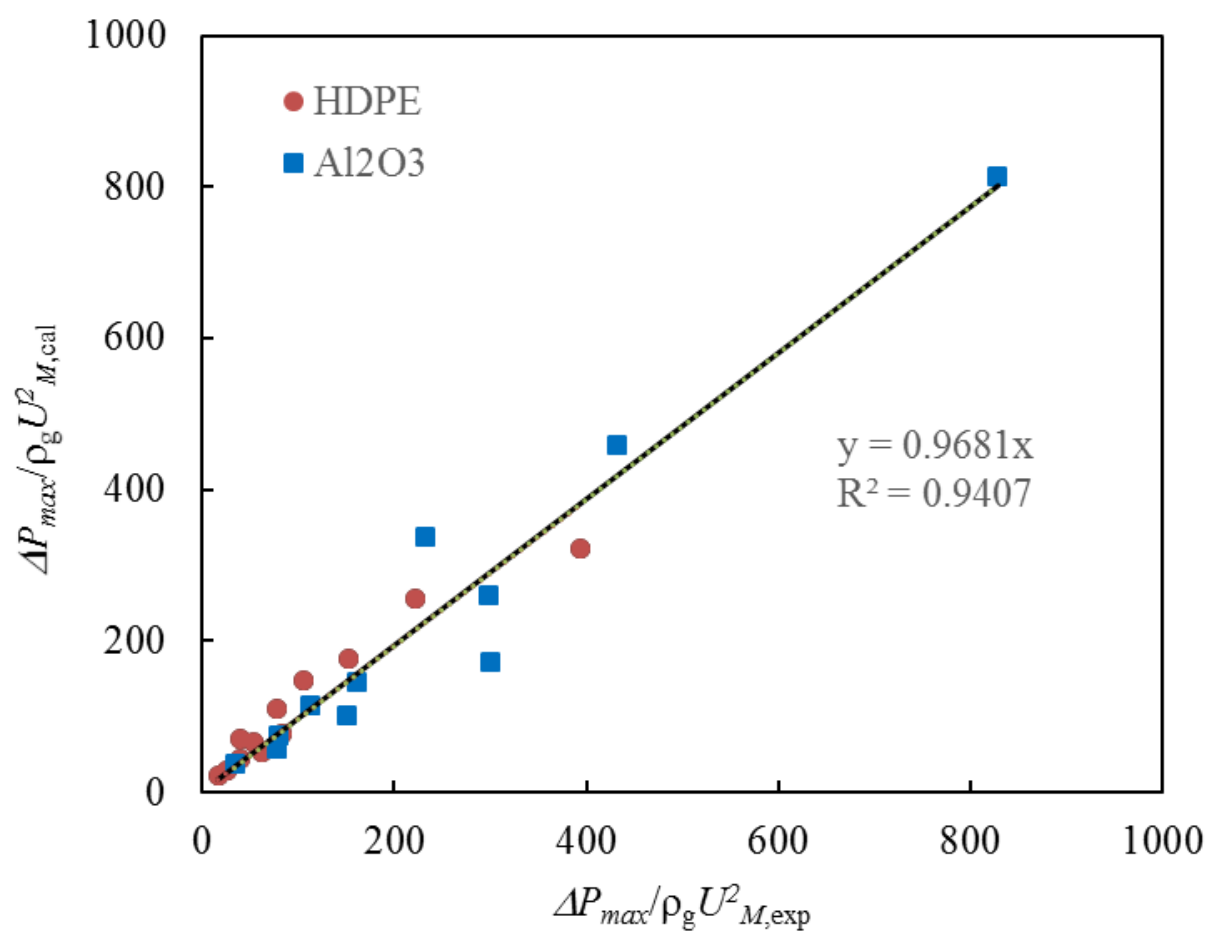

Figure 15. Comparison of the maximum pressure drop ratio for spouted fluid bed using Eq. (10) with experimentally measured values.

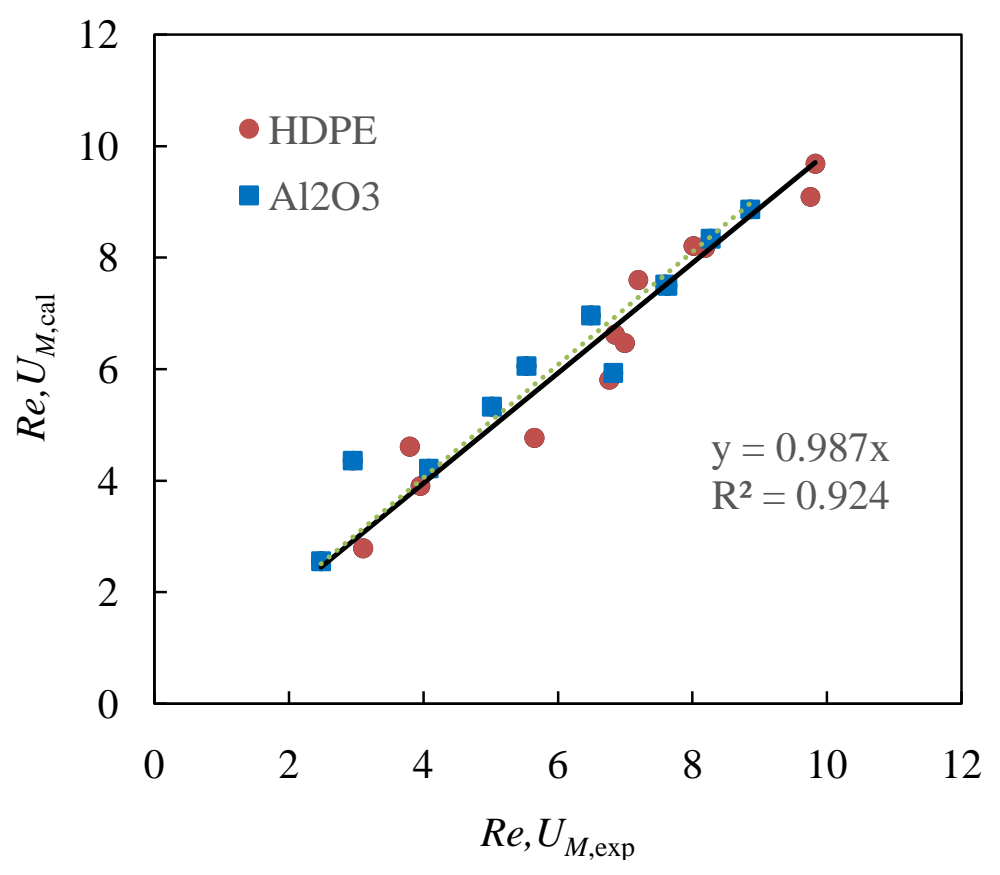

Figure 16. Comparison of the Re\# at maximum pressure drop for spouted fluid bed using Eq. (11) with experimentally measured values. 